BIOSFER: JURNAL PENDIDIKAN BIOLOGI (BIOSFERJPB)

2016, Volume 9 No 1, 40-46

ISSN: 0853-2451

\title{
HUBUNGAN ANTARA PENGETAHUAN SISWA TENTANG KONSEP-KONSEP EKOLOGI DENGAN ECOLOGICAL FOOTPRINT DIDASARKAN PADA GENDER (STUDI KORELASIONAL TERHADAP SISWA DI SMAN 31 JAKARTA)
}

Correlation between Student's Knowledge of Ecology Concepts with Ecological Footprint Based on Gender (Correlational Study Toward Student of 31 High School Jakarta)

\author{
Diana Vivanti, I Made Putrawan, Tania Agnesa \\ Pendidikan Biologi Fakultas MIPA Universitas Negeri Jakarta \\ Email: dianavivanti@yahoo.com
}

\begin{abstract}
Ecological footprint is an estimation analysis or measure individual consumption behaviour resulting in the environment. One of the factors which ecological footprint affects are knowledge of ecology concepts and gender. The objective of this research was to determine the relationship between student's knowledge of ecology concepts to ecological footprint based on gender. This research was conducted on January-February 2016. The method used was descriptive method with correlational study. The sample was simple random sampling about 104 students. The prerequisite test showed that the data was normal and homogen. The first hypothesis test using linear regression test and simple correlation. Regression model obtained $\hat{Y}=0.047-0.574 \mathrm{X}$ had a significant and linear relationship. The coefficient of correlation obtained was -0.72 , which means there was a negative relationship between student's knowledge of ecology concepts to ecological footprint. The coefficient of determination obtained was .518, which means student's knowledge of ecology concepts contributed $51.8 \%$ to the ecological footprint. The second hypothesis test using t-test independent sample, significance value obtained was .123, which means that there was no significant ecological footprint difference between man students and woman students. The result of this study concluded that there was negative correlation between student's knowledge of ecology concepts with ecological footprint and gender was no affect the student's ecological footprint. The higher of knowledge of ecology concepts will reduce their ecological footprint and it will create a balance environment.
\end{abstract}

Keyword : Knowledge, ecology concepts, gender, ecological footprint

\section{PENDAHULUAN}

Pola konsumsi manusia akan makin bertambah seiring dengan adanya pertumbuhan ekonomi. Pola konsumsi tersebut dipengaruhi oleh adanya keinginan untuk memenuhi kebutuhan dasar manusia. Adanya peningkatan dalam mengkonsumsi berbagai jenis kebutuhan secara berlebihan akan berdampak pada ketidakseimbangan lingkungan. Hal tersebut dikarenakan perilaku konsumsi yang meningkat akan meningkatkan pula kegiatan produksi berbagai jenis kebutuhan. 
Analisis untuk mengestimasi konsumsi sumber daya alam dan penguraian limbah untuk menunjang populasi adalah analisis ecological footprint. Ecological footprint merupakan salah satu pendekatan untuk mengkaji batas-batas keberlanjutan suatu ekosistem dengan mengukur permintaan masyarakat atas alam dalam area global biokapasitas (Wackernagel\&Rees, 1994). Perhitungan ecological footprint dapat dilakukan dengan dua pendekatan yaitu dengan metode compound dan component-based (Simmons, et.al., 2000). Ecological footprint mengukur perilaku konsumsi individu yang berdampak pada lingkungan seperti konsumsi sumber daya alam dan penguraian limbah yang dihasilkan, semua diukur berdasarkan sudut pandang area lahan yang dibutuhkan.

Perilaku individu dalam konsumsi produk kebutuhan dapat dipengaruhi oleh pengetahuan dan faktor sosial yaitu gender. Pengetahuan dapat diartikan sebagai keseluruhan pemikiran, gagasan, ide, konsep dan pemahaman yang dimiliki oleh manusia (John Locke, 1690). Pengertian ekologi adalah pengkajian hubungan organismeorganisme atau kelompok-kelompok organisme terhadap lingkungannya (Odum, 1993). Gender didefinisikan sebagai gambaran karakteristik yang dijalankan oleh pria atau wanita dalam menghadapi kehidupan sosial dan kebudayaan melalui proses sosialisasi (Wharton, 2005). Makin tinggi pengetahuan mengenai lingkungan maka kepedulian tentang kualitas lingkungan dan motivasi dalam partisipasi perilaku lingkungan yang bertanggung jawab makin tinggi pula. Adanya perbedaan gender dalam kehidupan sosial juga dapat mempengaruhi pola konsumsi.

Oleh karena itu, atas dasar pemikiran tersebut diduga terdapat hubungan yang negatif antara pengetahuan tentang konsep ekologi dengan ecological footprint didasarkan pada gender.

\section{METODELOGI PENELITIAN}

Penelitian ini menggunakan metode deskriptif melalui studi korelasional. Variabel bebas $(\mathrm{X})$ pada penelitian ini adalah pengetahuan siswa tentang konsep-konsep ekologi dan gender, sedangkan variabel terikat $(\mathrm{Y})$ adalah ecological footprint. Penelitian ini dilaksanakan di SMA Negeri 31 Jakarta, pada bulan Januari - Februari 2016. Sampel yang digunakan pada penelitian ini adalah 104 siswa SMAN 31 Jakarta yang ditentukan dengan cara simple random sampling. Pengujian hipotesis pertama menggunakan pengujian regresi linier sederhana, sedangkan pengujian hipotesis kedua menggunakan uji-t independet samples.

\section{HASIL PENELITIAN}

Berdasarkan data yang diperoleh dari 104 siswa, skor tertinggi yang diperoleh adalah 90 dan skor terendah adalah 67 dari rentang skor 0-100. Berdasarkan hasil perhitungan, diperoleh rata-rata skor sebesar 81 dengan simpangan baku sebesar 5,59. Skor yang memiliki frekuensi tertinggi berada pada rentang kelas 85-87 yaitu sebanyak 29 siswa dengan frekuensi relatif sebesar 27,88\%. Skor yang memiliki frekuensi terendah berada pada rentang kelas 67-69 yaitu sebanyak 2 siswa dengan frekuensi relatif sebesar 1,92\%. Pada Gambar 1 dapat dilihat distribusi frekuensi skor pengetahuan siswa tentang konsepkonsep ekologi. 


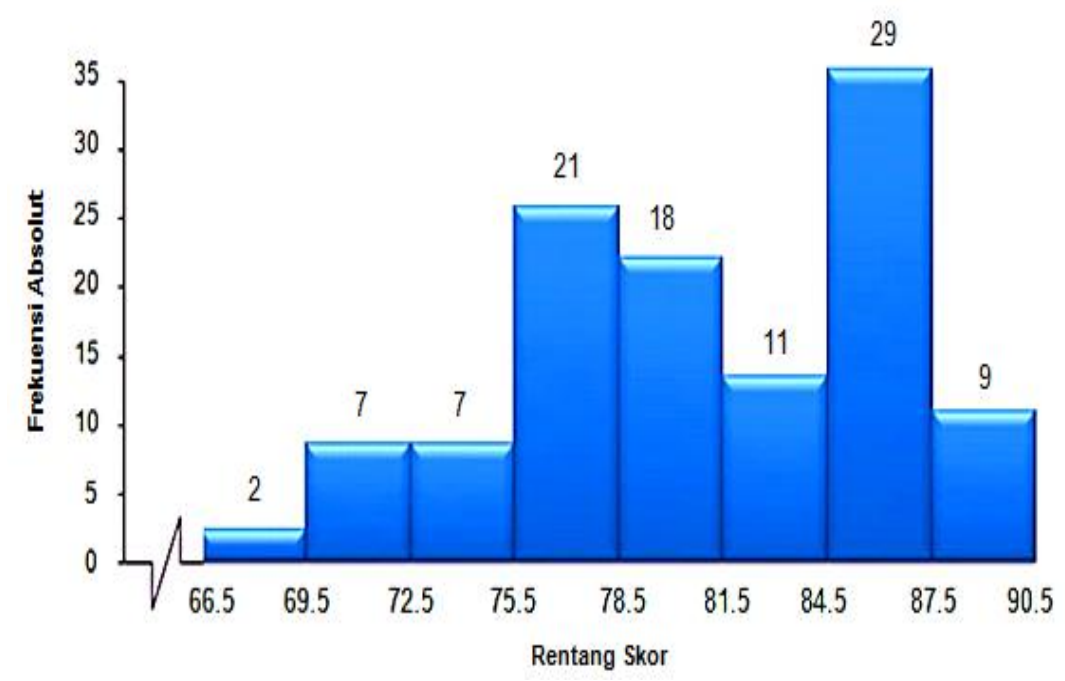

Gambar 1. Distribusi Frekuensi Skor Pengetahuan Tentang Konsep Ekologi

Berdasarkan hasil pengukuran total ecological footprint dari 104 siswa di sekolah diperoleh besaran ecological footprint terendah sebesar 0,0107 gha dan besaran ecological footprint tertinggi adalah 1,8539 gha. Rata-rata total ecological footprint individu sebesar 0,4376 gha. Pada Gambar 2 dapat dilihat perbandingan rata-rata ecological footprint siswa.

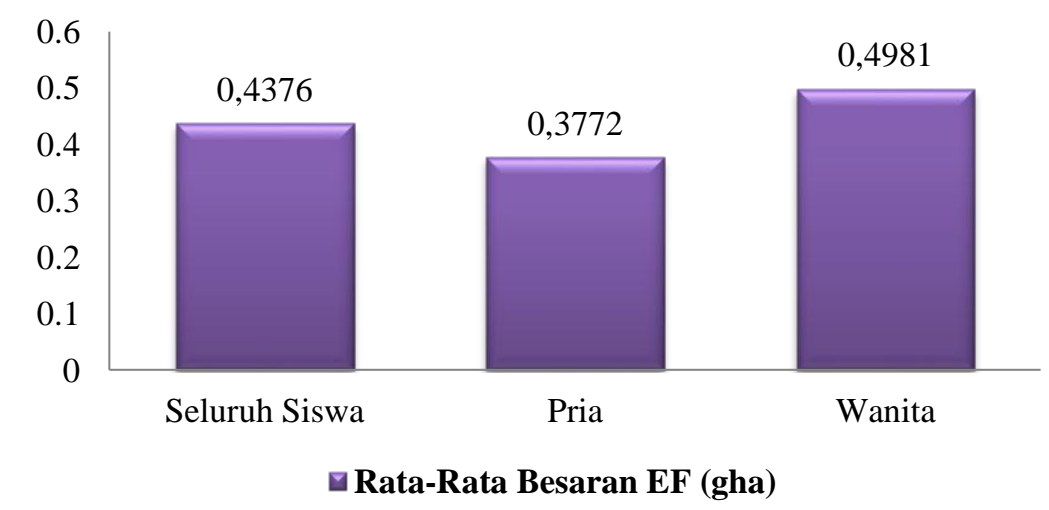

Gambar 2. Perbandingan Rata-Rata Ecological Footprint Siswa

Kontribusi total ecological footprint terbesar siswa adalah komponen transportasi yaitu 45,42 gha dan terendah adalah komponen air yaitu 0,101 gha. Pada Gambar 3 dapat dilihat total ecological footprint seluruh siswa berdasarkan komponen. 


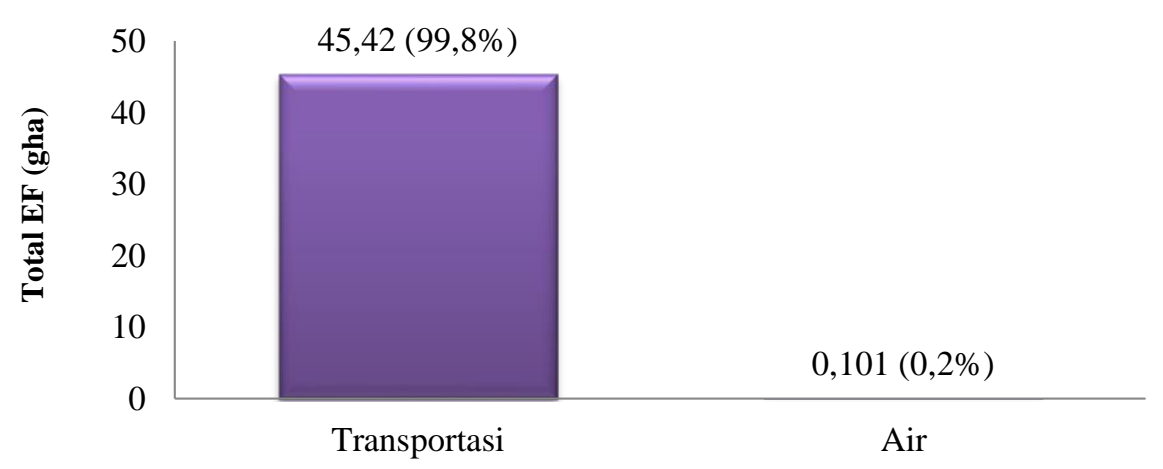

Gambar 3. Total Ecological Footprint Seluruh Siswa Berdasarkan Komponen

Siswa yang dipersepsi bergender pria memiliki besaran rata-rata total EF yang lebih rendah pada komponen transportasi dan air dibandingkan dengan siswa yang dipersepsi bergender wanita. Besarnya perbedaan rata-rata ecological footprint siswa yang dipersepsi bergender pria dan siswa yang dipersepsi bergender wanita pada komponen transportasi adalah 0,120 gha, sedangkan pada komponen air adalah 0,0001 gha. rata-rata ecological footprint tiap komponen berdasarkan gender dapat dilihat pada Gambar 4.

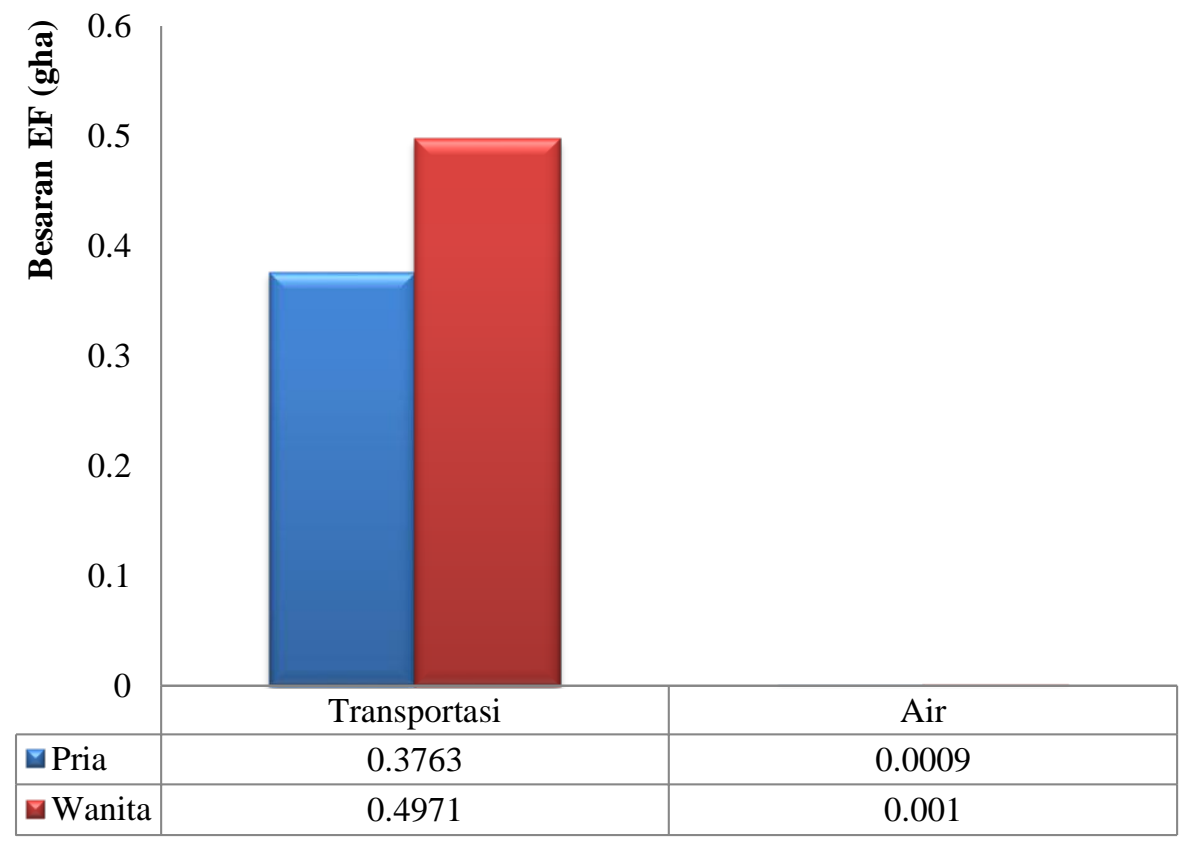

Gambar 4. Rata-Rata Ecological Footprint Tiap Komponen Berdasarkan Gender

Model regresi linier yang diperoleh adalah $\hat{Y}=0,047-0,574 X$ dengan analisis varians regresi linier sederhana tertera pada Tabel 1. 
Tabel 1. Analisis Varians Regresi Linier Sederhana Model Regresi $\hat{Y}=0,047$ $0,574 \mathrm{X}$

\begin{tabular}{|c|c|c|c|c|c|c|}
\hline \multirow{2}{*}{$\begin{array}{l}\text { Sumber } \\
\text { Variasi }\end{array}$} & \multirow{2}{*}{$\mathrm{dk}$} & \multirow{2}{*}{$\mathrm{jk}$} & \multirow{2}{*}{$R j k$} & \multirow{2}{*}{$\mathrm{F}_{\text {hitung }}$} & \multicolumn{2}{|l|}{$\mathrm{F}_{\text {tabel }}$} \\
\hline & & & & & 0,05 & 0,01 \\
\hline Total $(\mathrm{T})$ & 104 & 65,640 & 65,640 & \multirow{4}{*}{$171,422 * *$} & \multirow{4}{*}{3,93} & \multirow{4}{*}{6,89} \\
\hline Regresi (a) & 1 & 0,230 & 0,230 & & & \\
\hline Regresi (b/a) & 1 & 40,970 & 40,970 & & & \\
\hline Sisa (S) & 102 & 24,443 & 0,239 & & & \\
\hline $\begin{array}{l}\text { Tuna cocok } \\
\text { (TC) }\end{array}$ & 8 & 1,530 & 0,191 & \multirow{2}{*}{$0,786^{\mathrm{ns}}$} & \multirow{2}{*}{2,04} & \multirow{2}{*}{2,71} \\
\hline Galat (Eror) & 94 & 22,919 & 0,243 & & & \\
\hline
\end{tabular}

Keterangan : sangat signifikan; non signifikan

Diagram berikut menggambarkan hubungan antara pengetahuan siswa tentang konsepkonsep ekologi dengan ecological footprint.

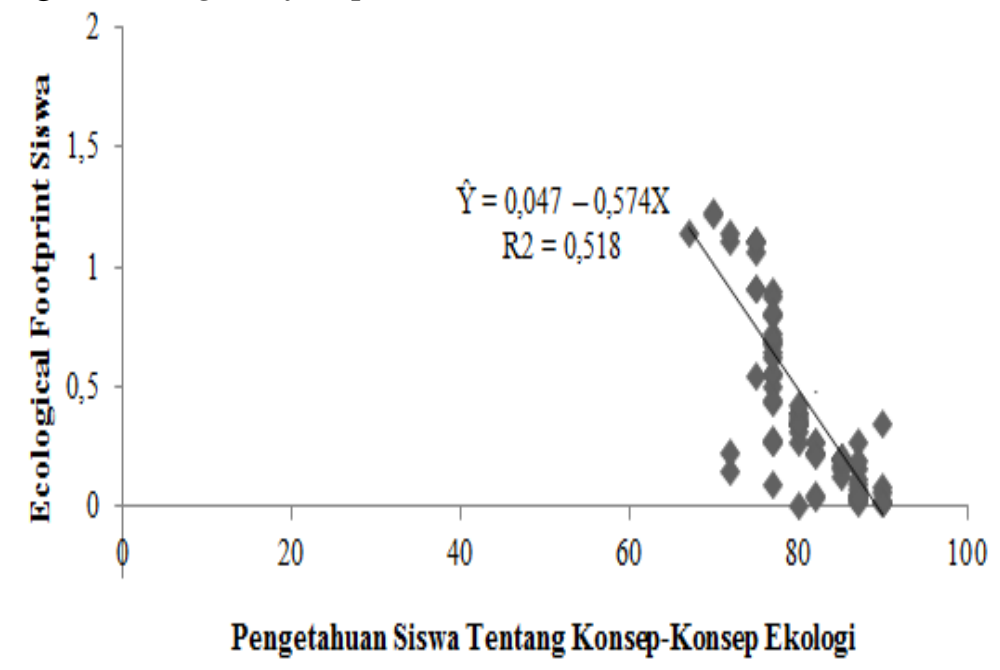

Gambar 5. Model Regresi Linier antara Pengetahuan Siswa tentang Konsep-Konsep Ekologi dengan Ecological Footprint

Berdasarkan hasil perhitungan, didapatkan koefisien korelasi $\left(\mathrm{r}_{\mathrm{xy}}\right)$ adalah $-0,72$. Tanda korelasi negatif menunjukkan adanya nilai tinggi pada satu variabel dan rendah pada variabel lainnya. Koefisien determinasi $\left(\mathrm{r}^{2}\right)$ berdasarkan perhitungan sebesar 0,518. Artinya $51,8 \%$ variabel ecological footprint dapat ditentukan oleh variabel pengetahuan siswa tentang konsep-konsep ekologi, sedangkan 48,2\% disebabkan oleh faktor lain.

Berdasarkan hasil uji t-independent samples diperoleh besaran signifikansi 0,123. Hal tersebut menunjukkan bahwa, terdapat perbedaan yang tidak signifikan antara 
ecological footprint siswa yang dipersepsi bergender pria dan ecological footprint siswa yang dipersepsi bergender wanita.

\section{PEMBAHASAN}

Berdasarkan hasil analisis dapat diketahui bahwa, terdapat hubungan negatif antara pengetahuan siswa tentang konsep-konsep ekologi dengan ecological footprint. Hal ini sesuai dengan pernyataan dimana ecological footprint individu yang cenderung rendah berbanding terbalik dengan pengetahuan yang dimiliki individu (Brody, 1994).

Pengetahuan yang dimiliki siswa dapat mengubah pola perilaku konsumsi siswa. Siswa yang memiliki pengetahuan yang tinggi cenderung tidak boros dalam mengonsumsi produk kebutuhan. Hal ini sesuai dengan pernyataan bahwa pengetahuan ekologi dapat menyebabkan terjadinya perubahan sikap manusia yang secara langsung mempengaruhi pola perilaku (I Made Putrawan, 2015).

Pada pengujian antara ecological footprint siswa yang dipersepsi bergender pria dan siswa yang dipersepsi bergender wanita menunjukan tidak adanya perbedaan.

Tidak adanya perbedaan antara ecological footprint siswa yang dipersepsi bergender pria dan siswa yang dipersepsi bergender wanita disebabkan adanya kesetaraan gender (gender equality) pada siswa di perkotaan seperti Jakarta. Kesetaraan gender adalah suatu keadaan dimana pria dan wanita memiliki kesempatan yang sama dalam proses kehidupan (Johnsson, Gerd \& Latham, 2007).

Namun, berdasarkan hasil data statistik menunjukan bahwa variansi ecological footprint siswa yang dipersepsi bergender wanita lebih besar daripada siswa yang dipersepsi bergender pria. Keadaan tersebut memungkinkan terjadinya peningkatan besaran ecological footprint. Hal ini sesuai dengan penelitian Venus (2011), dimana variansi yang besar pada ecological footprint wanita menunjukan bahwa wanita tidak dapat mengontrol penggunaan sumber daya. Peningkatan besaran ecological footprint mungkin akan dapat lebih terlihat apabila pengukuran konsumsi ditinjau dari komponen lain selain transportasi dan air.

Rata-rata besaran total ecological footprint siswa adalah 0,4376 gha. Hal ini menunjukkan bahwa, setiap individu siswa di SMAN 31 Jakarta rata-rata membutuhkan lahan untuk menunjang semua aktivitasnya selama di sekolah seluas 0,4376 gha per tahun . Bila ditinjau dari besarnya ecological footprint Indonesia, yaitu 1,21 gha/individu dengan biokapasitasnya sebesar 1,35 gha/individu (Miller, 2012), maka rata-rata besaran total ecological footprint siswa tergolong rendah. Hal ini dikarenakan, besarnya ecological footprint siswa tidak melampaui kemampuan biokapasitas pada suatu wilayah.

Besarnya ecological footprint pada komponen transportasi lebih tinggi daripada air. Hal ini menunjukkan bahwa, siswa membutuhkan lahan untuk menyerap karbon atau lahan yang diperlukan untuk mengabsorbsi $\mathrm{CO}_{2}$ dari aktivitas penggunaan transportasi lebih tinggi dibandingkan aktivitas penggunaan air.

\section{KESIMPULAN}

Berdasarkan hasil penelitian maka dapat disimpulkan bahwa terdapat hubungan negatif antara pengetahuan siswa tentang konsep-konsep ekologi dengan ecological footprint. Artinya makin tinggi tingkat pengetahuan siswa tentang konsep-konsep ekologi maka makin rendah besaran ecological footprint siswa. Selain itu, tidak terdapat perbedaan 
antara ecological footprint siswa yang dipersepsi bergender pria dan siswa yang dipersepsi bergender wanita.

\section{DAFTAR PUSTAKA}

Brody, M. (1994). Student Science Knowledge Related to Ecological Crises. International Journal Science Education, 16, 24-33.

Johnsson-Latham, G. (2007). A Study on Gender Equality as A Prerequisite for Sustainable Development. Stockholm: The Environment Advisory Council

Locke, John. (1690). An Essay Concerning Human Understanding. USA: Pennsylvania State University.

Odum. (1993). Fundamentals of Ecology Third Edition. Philadelphia: W.B. Saunders.

Putrawan, I Made. (2015). Measuring New Environmental Paradigm Based on Student Knowledge About Ecosystem and Locus of Control. Eurasia Journal of Mathematics, Science and Technology Education, 11(2), 325-333.Capacity: A Tool For Planning Toward Sustainability. Canada: The University of British Columbia.

Simmons, C., Lewis, K., \& Barrett, J. (2000). Two feet-two approaches: a componentbased model of ecological footprinting. Ecological economics, 32(3), 375-380

Solar, Venus. (2011). Comparative Study on Male and Female Personal Ecological Footprint. International Conference on Biotechnology and Environmet Management, 2(5).

Wackernagel, Mathis. (1994). Ecological Footprint And Appropriated Carrying Capacity: A Tool For Planning Toward Sustainability. Canada: The University of British Columbia.

Wharton, A. S. (2005). The sociology of gender: An Introduction to Theory and Research. United Kingdom: Blackwell Publishing 